\title{
Organic Delusional Syndrome
}

National Cancer Institute

\section{Source}

National Cancer Institute. Organic Delusional Syndrome. NCI Thesaurus. Code C34869.

A mental disorder caused by intrinsic disease which is characterized by persistent or recurrent irrational beliefs. Consciousness and memory are not affected. It may be broadly classified as a psychotic disorder due to a general medical condition. 